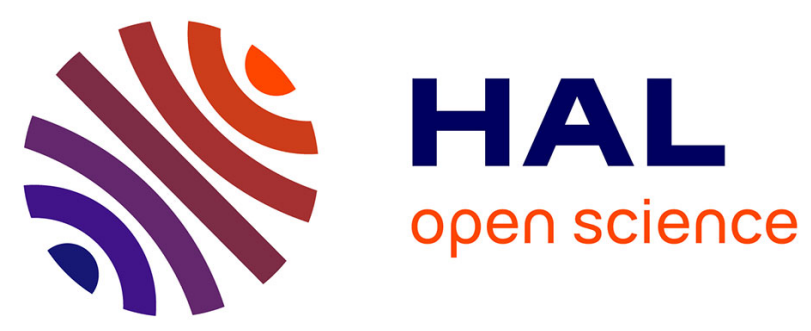

\title{
Inhibitory Effects of Ethanol in the Neonatal Rat Hippocampus In Vivo
}

Kseniya Chernova, Gulshat Burkhanova, Andrey Zakharov, Roustem Khazipov, Guzel Sitdikova

\section{- To cite this version:}

Kseniya Chernova, Gulshat Burkhanova, Andrey Zakharov, Roustem Khazipov, Guzel Sitdikova. Inhibitory Effects of Ethanol in the Neonatal Rat Hippocampus In Vivo. BioNanoScience, 2017, 7 (1), pp.159-161. 10.1007/s12668-016-0328-4 . hal-01962095

\section{HAL Id: hal-01962095 https://hal-amu.archives-ouvertes.fr/hal-01962095}

Submitted on 20 Dec 2018

HAL is a multi-disciplinary open access archive for the deposit and dissemination of scientific research documents, whether they are published or not. The documents may come from teaching and research institutions in France or abroad, or from public or private research centers.
L'archive ouverte pluridisciplinaire HAL, est destinée au dépôt et à la diffusion de documents scientifiques de niveau recherche, publiés ou non, émanant des établissements d'enseignement et de recherche français ou étrangers, des laboratoires publics ou privés.

\section{(c)(1)}

Distributed under a Creative Commons Attribution| 4.0 International License 


\title{
Inhibitory Effects of Ethanol in the Neonatal Rat Hippocampus In Vivo
}

\author{
Kseniya Chernova $^{1} \cdot$ Gulshat Burkhanova $^{1}$ - Andrey Zakharov ${ }^{1,2}$ (1) \\ Roustem Khazipov ${ }^{1,3,4} \cdot$ Guzel Sitdikova $^{1}$
}

Published online: 12 October 2016

(C) Springer Science+Business Media New York 2016

\begin{abstract}
Ethanol-induced neuroapoptosis in the developing brain has been suggested to involve suppression of neuronal activity. However, ethanol acts as a potent stimulant of neuronal activity by increasing the frequency of depolarizing GABA dependent giant depolarizing potentials in the neonatal rat hippocampal slices in vitro. Here, we show that ethanol strongly inhibits, in a dose-dependent manner $(1-6 \mathrm{~g} / \mathrm{kg}$ ), sharp waves and multiple unit activity in the hippocampus of neonatal (postnatal days P4-6) rats in vivo. Thus, the effects of ethanol on the developing hippocampal network activity cardinally differ in vitro (stimulation) and in vivo (inhibition).
\end{abstract}

Keywords Electroencephalography · Ethanol ·

Hippocampus $\cdot$ Sharp waves $\cdot$ Rat $\cdot$ Neonate

\section{Introduction}

Ethanol and general anesthetics induce massive neuroapoptosis in the developing brain $[1,2]$. Considerable evidence obtained in the neocortex indicates that the neuroapoptotic effects of these drugs involve suppression of the early activity patterns and the neuronal activity [3-5]. However, ethanol has also been

Andrey Zakharov

AnVZaharov@kpfu.ru

1 Laboratory of Neurobiology, Kazan Federal University, 18 Kremlevskaya str., Kazan 420008, Russia

2 Department of Physiology, Kazan State Medical University, Kazan 420012, Russia

3 INMED - INSERM U901, 163 avenue de Luminy, Marseille 13273, France

4 Aix-Marseille University, Marseille 13273, France shown to increase the frequency of depolarizing GABA driven giant depolarizing potentials and to act as a potent stimulator of the neuronal activity in the neonatal rat hippocampal slices in vitro [6]. These findings go against the hypothesis that the adverse effects of ethanol in the neonatal hippocampus involve suppression of an activity. Yet, the effects of ethanol on the early hippocampal activity so far have not been addressed in vivo. The aim of this study was to characterize the effects of ethanol on the electrographic activity and the neuronal firing in the hippocampus of neonatal rat pups in vivo.

\section{Material and Methods}

This work has been carried out in accordance with EU Directive 2010/63/EU for animal experiments and all animal-use protocols were approved by the French National Institute of Health and Medical Research (INSERM, protocol N007.08.01) and Kazan Federal University on the use of laboratory animals (ethical approval by the Institutional Animal Care and Use Committee of Kazan State Medical University N9-2013). Wistar rats from postnatal day (P) P4-P6 were used. Surgery was performed under isoflurane anesthesia, and the animals were left to recover from anesthesia for more than one hour before the recordings. Preparation of the animals for the head-restrained recordings and the recording setups were as described previously [3]. Recordings of the sharp waves (SPWs) on the local field potential (LFP) and the multiple unit activity (MUA) were performed from the hippocampus using linear silicone probes (16 channels, $100 \mu \mathrm{m}$ separation distance between the recording sites, Neuronexus Technologies, USA). The signals were amplified and filtered $(\times 10,000 ; 0.1-10 \mathrm{kHz})$ using a DigitalLynx (Neuralynx, USA) amplifier, digitized at $32 \mathrm{kHz}$ and saved on a PC for post-hoc analysis using custom-written functions 
in Matlab (MathWorks, USA) as described previously [3]. The Mann-Whitney and $t$ tests were used for the group data comparisons with a level of significance set at $p<0.05$.

\section{Results and Discussion}

The electrical activity of the hippocampus was characterized by SPWs which are the predominant electrographic activity pattern during the early postnatal period (Fig. 1a, b) [7]. In keeping with these previous studies, the SPWs synchronized CA1 units, reversed polarity at the pyramidal cell layer, as evidenced by the current source density analysis, and occurred irregularly at a frequency of $3.7 \pm 0.2 \mathrm{~min}^{-1}(n=9$; P4-6). The average MUA in the CA1 pyramidal cell layer estimated by a 1-h recording session prior to ethanol administration was $3.5 \pm 1.2 \mathrm{spikes} / \mathrm{s}$.

Ethanol was administered intraperitoneally at three dosage regimens: $1 \mathrm{~g} / \mathrm{kg}+3 \mathrm{~g} / \mathrm{kg}$ (with 1 -h interval), $4.5 \mathrm{~g} / \mathrm{kg}$, and $6 \mathrm{~g} / \mathrm{kg}$. At the maximal dosage $(6 \mathrm{~g} / \mathrm{kg})$, ethanol-induced rapid and profound inhibition of the hippocampal activity (Fig. 1a, c, d). Thirty minutes after ethanol administration, SPWs and CA1 MUA were almost completely suppressed that was characterized by the reduction in SPWs frequency and MUA to $7.0 \pm 4.8$ and $2.3 \pm 1.8 \%$ of the control values, respectively $(n=3, p<0.05, t$ test). This was followed by partial recovery of the activity $3 \mathrm{~h}$ after the ethanol administration (SPWs frequency recovered to $32 \pm 6 \%$ and MUA to $15 \pm 11 \%$ of the control values; $n=3$ ). Ethanol at lower doses, $1+3 \mathrm{~g} / \mathrm{kg}$ with a $1-\mathrm{h}$ interval and $4.5 \mathrm{~g} / \mathrm{kg}$ produced less rapidly and less prominently, but also the long-lasting

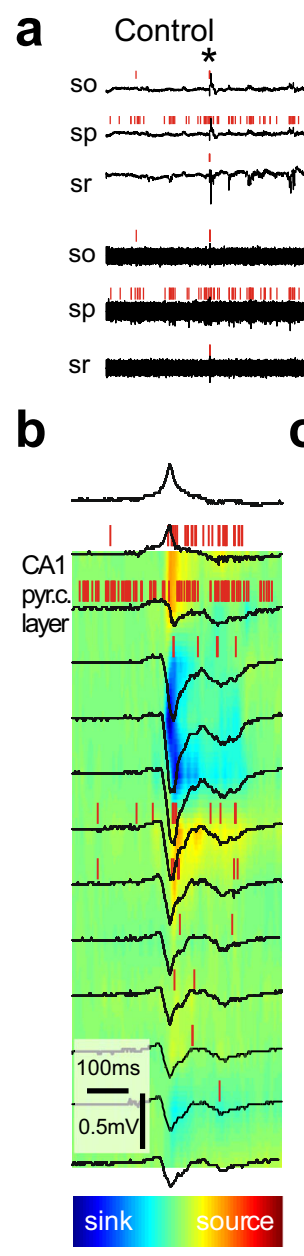

Ethanol

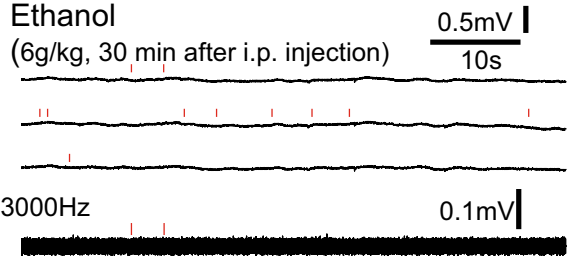

LFP $300-3000 \mathrm{H}$
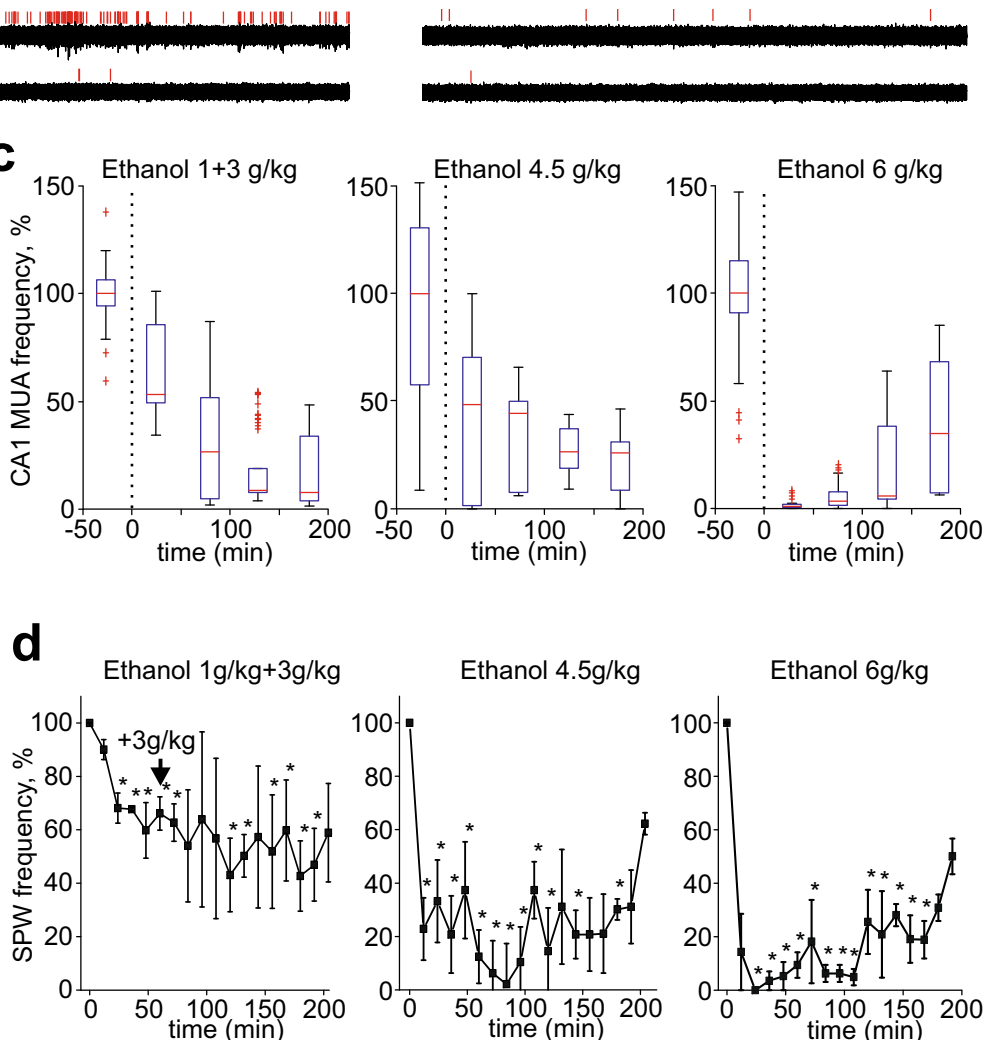

Fig. 1 Effects of ethanol on the electrical activity in newborn rat hippocampus in vivo. a Example traces of CA1 hippocampal activity at different depths in a P6 rat before (left) and 30 min after the administration of ethanol (right). Original and $300 \mathrm{~Hz}$ highpass filtered LFP_black traces, MUA — red bars. Sharp waves (SPWs) are marked by asterisks. Hippocampal layers stratum pyramidale, stratum oriens, and stratum

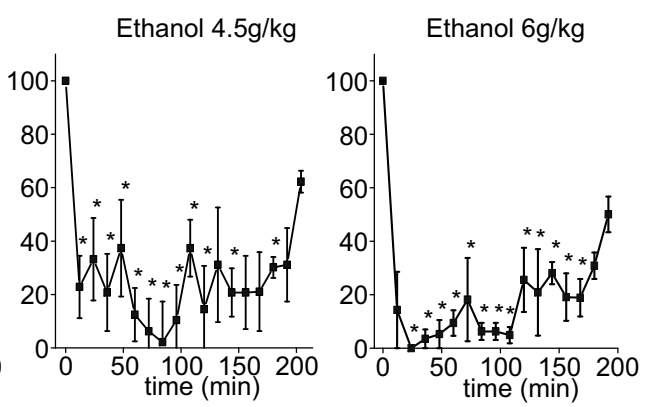

radiatum are indicated as $s p, s o$, and $s r$, respectively. $\mathbf{b}$ Example of the SPW and its current source density. c-d Time course of the CA1 pyramidal cell layer MUA frequency (c) and the SPWs frequency (d) after ethanol administration at $1 \mathrm{~g} / \mathrm{kg}+3 \mathrm{~g} / \mathrm{kg}, 3 \mathrm{~g} / \mathrm{kg}, 6 \mathrm{~g} / \mathrm{kg}$ (i.p.) during the 3 -h recordings. Significant differences from the control values $(p<0.05)$ are indicated by the asterisks (Mann-Whitney test) 
suppression of the hippocampal activity. Thirty minutes after ethanol administration at dosage $4.5 \mathrm{~g} / \mathrm{kg}$ MUA decreased to $30 \pm 26 \%$ and SPWs frequency reduced to $25 \pm 4 \%$ of the control values ( $n=3, p<0.05, t$ test). At dosage $1 \mathrm{~g} / \mathrm{kg}$, MUA showed a tendency to decrease to $61 \pm 13 \%$ of the control values but this was not significant $(n=3, p>0.05, t$ test) whereas SPWs frequency reduced to $29 \pm 2 \%$ of the control values $(n=3, p<0.05, t$ test). These results indicate that ethanol induces rapid suppression of the hippocampal activity in the rat pups and that the effects of ethanol are dose-dependent. The inhibitory effects of ethanol were long-lasting so that by $3 \mathrm{~h}$ after the injection, the electrical activity was still suppressed and was significantly lower than in control before the ethanol injection (Fig. 1c, d).

Thus, ethanol at the doses inducing massive neuroapoptosis in the developing brain exerts powerful inhibitory actions on SPWs and neuronal firing in the neonatal rat hippocampus. These results differ from the stimulation of the activity described in the hippocampal slices of the neonatal rats in vitro, where ethanol was shown to increase the frequency of depolarizing GABA driven giant depolarizing potentials [6]. Although the reasons for this sharp discrepancy in the ethanol actions in vivo and in vitro are unknown, it is plausible that it involves an increase in GABAergic transmission by ethanol [6], which exerts, during the neonatal period, complex excitatory and inhibitory network actions in the hippocampus in vitro $[8,9]$, but mainly inhibitory network actions in cortical circuits of neonatal rodents in vivo [10-12]. Another mechanism could involve respiratory acidosis which was shown to suppress giant depolarizing potentials in the neonatal rat hippocampal slices [13]. However, in our previous study, ethanol at the maximal dosage of $6 \mathrm{~g} / \mathrm{kg}$ did not affect oxygen saturation $\left(\mathrm{SpO}_{2}\right)$, breath rate and heart rate in the neonatal rats under similar experimental conditions [4]. Independently on the underlying mechanisms, our results support the hypothesis that ethanol-induced hippocampal neuroapoptosis during the neonatal period involves suppression of neuronal activity $[14,15]$.

\section{Conclusion}

Our main finding is that ethanol strongly suppresses activity in the neonatal rat hippocampus in a dose-dependent manner similarly to the ethanol actions previously described for the somatosensory cortex [4]. These results provide mechanistic support to the hypothesis that the neuroapoptotic actions of ethanol and general anesthetics involve severe suppression and particular vulnerability of the early activity patterns to these drugs.

Acknowledgments This work was supported by the Program of Competitive Growth of Kazan Federal University, the subsidy allocated to Kazan Federal University for the state assignment in the sphere of scientific activities and by INSERM (LIA).

\section{References}

1. Ikonomidou, C., Bittigau, P., Ishimaru, M. J., Wozniak, D. F., Koch, C., Genz, K., et al. (2000). Ethanol-induced apoptotic neurodegeneration and fetal alcohol syndrome. Science, 287, 1056-1060.

2. Ikonomidou, C., Bosch, F., Miksa, M., Bittigau, P., Vockler, J., Dikranian, K., et al. (1999). Blockade of NMDA receptors and apoptotic neurodegeneration in the developing brain. Science, $283,70-74$

3. Sitdikova, G., Zakharov, A., Janackova, S., Gerasimova, E., Lebedeva, J., Inacio, A. R., et al. (2014). Isoflurane suppresses early cortical activity. Annals of Clinical Translational Neurology, $1,15-26$.

4. Lebedeva, J., Zakharov, A., Ogievetsky, E., Minlebaeva, A., Kurbanov, R., Gerasimova, E., Sitdikova, G., and Khazipov, R. (2015) Inhibition of Cortical Activity and Apoptosis Caused by Ethanol in Neonatal Rats In Vivo. Cereb Cortex. doi:10.1093 /cercor/bhv293

5. Lebedeva, Y. A., Zakharova, A. V., Sitdikova, G. F., Zefirov, A. L., Khazipov, R. N. (2016). Ketamine-midazolam anesthesia induces total inhibition of cortical activity in the brain of newborn rats. Bulletin of Experimental Biology and Medicine, 161, 15-19.

6. Galindo, R., Zamudio, P. A., Valenzuela, C. F. (2005). Alcohol is a potent stimulant of immature neuronal networks: implications for fetal alcohol spectrum disorder. Journal of Neurochemistry, 94, 1500-1511.

7. Leinekugel, X., Khazipov, R., Cannon, R., Hirase, H., Ben Ari, Y., Buzsaki, G. (2002). Correlated bursts of activity in the neonatal hippocampus in vivo. Science, 296, 2049-2052.

8. Ben Ari, Y., Gaiarsa, J. L., Tyzio, R., Khazipov, R. (2007). GABA: a pioneer transmitter that excites immature neurons and generates primitive oscillations. Physiological Reviews, $87,1215-1284$.

9. Khalilov, I., Minlebaev, M., Mukhtarov, M., Khazipov, R. (2015). Dynamic changes from depolarizing to hyperpolarizing GABAergic actions during giant depolarizing potentials in the neonatal rat hippocampus. Journal of Neuroscience, $35,12635-12642$.

10. Minlebaev, M., Ben-Ari, Y., Khazipov, R. (2007). Network mechanisms of spindle-burst oscillations in the neonatal rat barrel cortex in vivo. Journal of Neurophysiology, 97, 692-700.

11. Kirmse, K., Kummer, M., Kovalchuk, Y., Witte, O. W., Garaschuk, O., Holthoff, K. (2015). GABA depolarizes immature neurons and inhibits network activity in the neonatal neocortex in vivo. Nature Communications, 6, 7750.

12. Valeeva, G., Tressard, T., Mukhtarov, M., Baude, A., Khazipov, R. (2016). An optogenetic approach for investigation of excitatory and inhibitory network GABA actions in mice expressing channelrhodopsin-2 in GABAergic neurons. Journal of Neuroscience, 36, 5961-5973.

13. Ruusuvuori, E., Kirilkin, I., Pandya, N., Kaila, K. (2010). Spontaneous network events driven by depolarizing GABA action in neonatal hippocampal slices are not attributable to deficient mitochondrial energy metabolism. Journal of Neuroscience, 30, 15638-15642.

14. Olney, John, W., (2014). Focus on apoptosis to decipher how alcohol and many other drugs disrupt brain development. Frontiers in Pediatrics, 2

15. Kilb, W., Kirischuk, S., Luhmann, H. J. (2011). Electrical activity patterns and the functional maturation of the neocortex. European Journal of Neuroscience, 34, 1677-1686. 